\section{Asymmetric Copper-Catalyzed Hydroamination of Aryl Alkynes}

\section{Key words}

asymmetric reductive

hydroamination

copper catalysis

enamines

hydrocupration

Reductive hydroamination of aryl alkynes (14 examples): Markovnikov selectivity<smiles>C#Cc1cccc(OC(=O)N(C)CC)c1</smiles>

A (1.0 equiv)

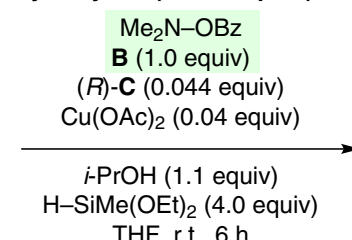

THF, r.t., $6 \mathrm{~h}$

$69 \%(1.0 \mathrm{mmol}$ scale $)$

$\mathrm{Bn}_{2} \mathrm{~N}-\mathrm{OBz}$

E (1.2 equiv)<smiles>CCOC(C#Cc1ccccc1)OCC</smiles>

D ( 1.0 equiv)

EtOH (1.5 equiv) -SiMe(OEt)

THF, $40{ }^{\circ} \mathrm{C}, 36 \mathrm{~h}$
$85 \%(10 \mathrm{mmol}$ scale $)$<smiles>CCN(C)C(=O)Oc1cccc(C(C)N(C)[Na])c1</smiles>

Rivastigmine $>99 \%$ ee

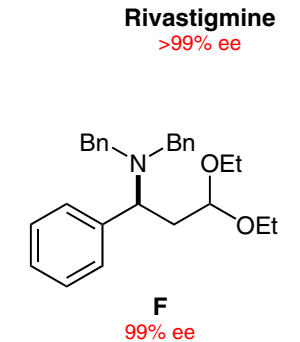

Reductive hydroaminaton of alkyl alkynes (9 examples): anti-Markovnikov selectivity<smiles>C#CC(c1ccccc1)c1cc(C)ccc1OC</smiles>

G (1.1 equiv)

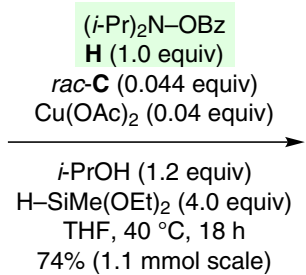

$74 \%(1.1 \mathrm{mmol}$ scale $)$

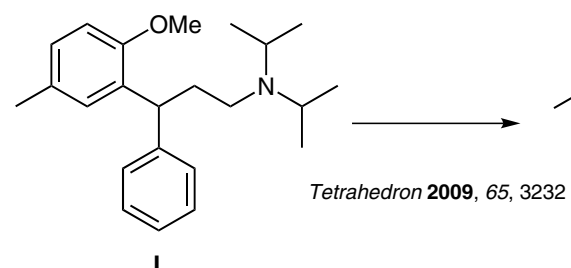

I

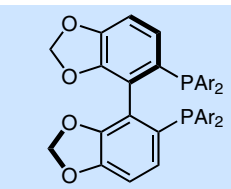

$(R)-\mathrm{C}$ $\mathrm{Ar}=3,5-(t-\mathrm{Bu})_{2}-4-\mathrm{OMe}-\mathrm{C}_{6} \mathrm{H}_{2}$
Significance: A new asymmetric synthesis of alkyl amines from readily available alkynes and electrophilic amine sources proceeds under mild conditions with high levels of regio- and stereocontrol. The regiochemistry of the initial hydrocupration reaction depends on the structure of the alkynes. Aryl alkynes display Markovnikov addition, whereas alkyl alkynes give anti-Markovnikov addition.
Comment: When the hydroamination reaction is performed in the absence of a proton source such as $i-\mathrm{PrOH}$ or $\mathrm{EtOH}$, enamine intermediates (not shown) are isolated in good yield (5 examples). Catalytic cycles for the enamine formation (direct hydroamination) and the reductive hydroamination reactions are proposed. A synthesis of rivastigmine exemplifies the value of the method.

SYNFACTS Contributors: Philip Kocienski

Synfacts 2015, 11(3), 0225 Published online: 16.02.2015

Dol: 10.1055/s-0034-1380075; Reg-No.: K00315SF 